\title{
FIRE DESIGN OF STEEL BEAMS WITH SLENDER CROSS-SECTION The influence of loading
}

\author{
Carlos Couto $^{\mathrm{a}}$, Paulo Vila Real ${ }^{\mathrm{a}}$, Nuno Lopes ${ }^{\mathrm{a}}$ and Bin Zhao ${ }^{\mathrm{b}}$ \\ ${ }^{a}$ RISCO -Department of Civil Engineering, University of Aveiro, Portugal \\ ${ }^{\mathrm{b}}$ CTICM - Centre Technique Industriel de la Construction Métallique, Paris, France
}

\begin{abstract}
The present paper addresses the study of laterally unrestrained steel beams with slendercrosssections for the case of fire with special focus on the influence of loading. A numerical investigation of several beams submitted to triangular and bi-triangular end-moment distribution and uniformly distributed loads is carried out at elevated temperatures usingshell finite elements. The results are compared with the existing simplified beam design rules of Part 1.2 of Eurocode 3 and recent developments on the subject, as well as the utilization of the factor " $f$ " which was developed to take into account the non-uniform bending diagrams but for stocky cross-sections (Class 1 and 2).
\end{abstract}

Keywords:Lateral torsional buckling (LTB), beams, class 4, fire, non-uniform bending

\section{INTRODUCTION}

The rules of EN1993-1-2 (CEN 2005) for designing laterally unrestrained beams with slender crosssections for the case of fire demonstrated to be very conservative (Couto et al. 2015a). This work was carried out within the European Research Project FIDESC4 (FIDESC4 2014)that has been funded by RFCS in order to improve this undesirable situation. In the referenced work, new design rules to assess the load bearing capacity of laterally unrestrained beams subjected to uniform bending moments were proposed based on an effective section factor that takes into account the interaction between local buckling and lateral-torsional buckling (LTB), which was identified as the main physical phenomena that influence the collapse of laterally unrestrained beams with slender cross-sections in case of fire. Herein, this new proposal is presented and its scope of application is expanded to take different loading cases into account, such as, triangular and bi-triangular bending moments and uniformly distributed loads. The consideration of factor " $f$ " that was developed for Class 1 and 2 beams (Vila Real et al. 2007; Lopes et al. 2010) is investigated to account for the influence of non-uniform bending diagrams in the resistance of beams with slender cross-sections against lateral-torsional buckling at elevated temperatures. Comparison with existing beam design rules of EN1993-1-2 is also performed and also with the consideration of factor " $f$ ".

An extensive numerical study is carried with GMNIA analysis at elevated temperatures using the software SAFIR (Franssen, 2005). Several cross-sections are considered as well as different temperatures. Comparisons, between numerical results and the simplified design rules to account for the influence of the loading, demonstrate a considerable improvement on the results leading to more accurate and, thus, economical fire design.

\subsection{Design methods for beams with slender cross-sections in fire situation}

The lateral-torsional buckling resistance of a beam with slender cross-section is evaluated in fire situation according to EN1993-1-2 with the following expression

$$
M_{b, f i, t, R d}=\chi_{L T, f i} M_{f i, \theta, R d} / \gamma_{M, f i}
$$


where $M_{f i, \theta, R d}$ is the design moment resistance of the cross-section for a uniform temperature $\theta$ and $\gamma_{M, f i}$ is the partial safety factor for fire situation.The reduction factor for LTB in the fire design situation is determined by

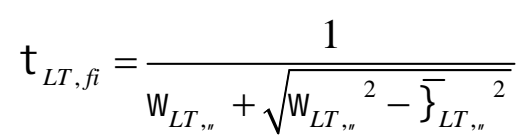

where $\bar{\lambda}_{L T, \theta}$ is the non-dimensional slenderness and $\phi_{L T, \theta}$ is the imperfection factor.

The imperfection factor is calculated as

$$
\phi_{L T, \theta}=0.5\left[1+\alpha_{L T}\left(\bar{\lambda}_{L T, \theta}-\bar{\lambda}_{L T, 0}\right)+\bar{\lambda}_{L T, \theta}^{2}\right]
$$

with the values of $\alpha_{L T}$ and $\bar{\lambda}_{L T, 0}$ given in Table 1 defining the EN1993-1-2 design curve and the three curves (L1, L2 and L3) proposed in (Couto et al. 2015a), see Fig. 1. Curves L1-L3 depend on the effective section factor $W_{e f f, y} / W_{e l, y}$ and the limits for its selection are also given in this table.

Table 1Parameters for the design curves for beams with slender cross-sections.

\begin{tabular}{|c|c|c|c|c|}
\hline Case & Curve & Limits & $\alpha_{L T}$ & $\bar{\lambda}_{L T, 0}$ \\
\hline 1 & EN1993-1-2 & Not applicable & $0.65 \varepsilon=0.65 \sqrt{235 / f_{y}}$ & 0.0 (no plateau) \\
\hline 2 & New proposal - L1 & $W_{e f f, y} / W_{e l, y}>0.9$ & $1.25 \varepsilon=1.25 \sqrt{235 / f_{y}}$ & 0.2 \\
\hline 3 & New proposal - L2 & $0.8<W_{e f f, y} / W_{e l, y} \leq 0.9$ & $1.00 \varepsilon=1.00 \sqrt{235 / f_{y}}$ & 0.2 \\
\hline 4 & New proposal - L3 & $W_{\text {eff, }, y} / W_{e l, y} \leq 0.8$ & $0.75 \varepsilon=0.75 \sqrt{235 / f_{y}}$ & 0.2 \\
\hline
\end{tabular}

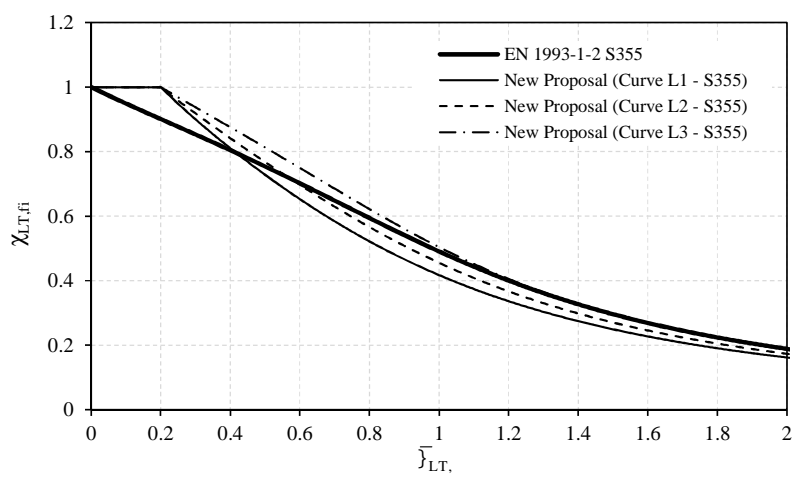

Fig. 1 Design curves for laterally unrestrained beams with slender cross-sections at elevated temperatures.

As mentioned in the introduction, in order to account with the non-uniform bending diagram, the factor " $f$ " may be used. In case of fire this factor is defined as

$$
f=1-0.5\left(1-k_{c}\right)
$$

where $k_{c}$ is a correction factor that depends on the moment distribution, and for beam submitted to end moments is given by

$$
k_{c}=0.6+0.3 \psi+0.15 \psi^{2} \text { but } k_{c} \leq 1
$$

and for a beam submitted to uniformly distributed load $k_{c}=0.91$. Finally, the reduction factor to take lateral-torsional buckling into account is calculated as

$$
\chi_{L T, f i, \bmod }=\frac{\chi_{L T, f i}}{f}
$$




\section{NUMERICAL INVESTIGATION}

The finite element computer code SAFIR (Franssen, 2005), was used with the numerical model depicted in Fig. 2 consideringa mesh with 10 elements in the flange, 22 elements in the web and 100 elements along the length. The loads were applied to the model using nodal forces, endmoments and uniformly distributed loads (applied in the lower flange) were considered. "Forksupport" conditions were modelled by restraining the vertical displacements of the bottom flange and out-of-the plane displacements of the web. The material model follows the stress-strain curve of EN1993-1-2 and the steel grade S355 was used, with a yield strength of $355 \mathrm{MPa}$, Young modulus of $210 \mathrm{GPa}$ and a poisson ratio of 0.3 .
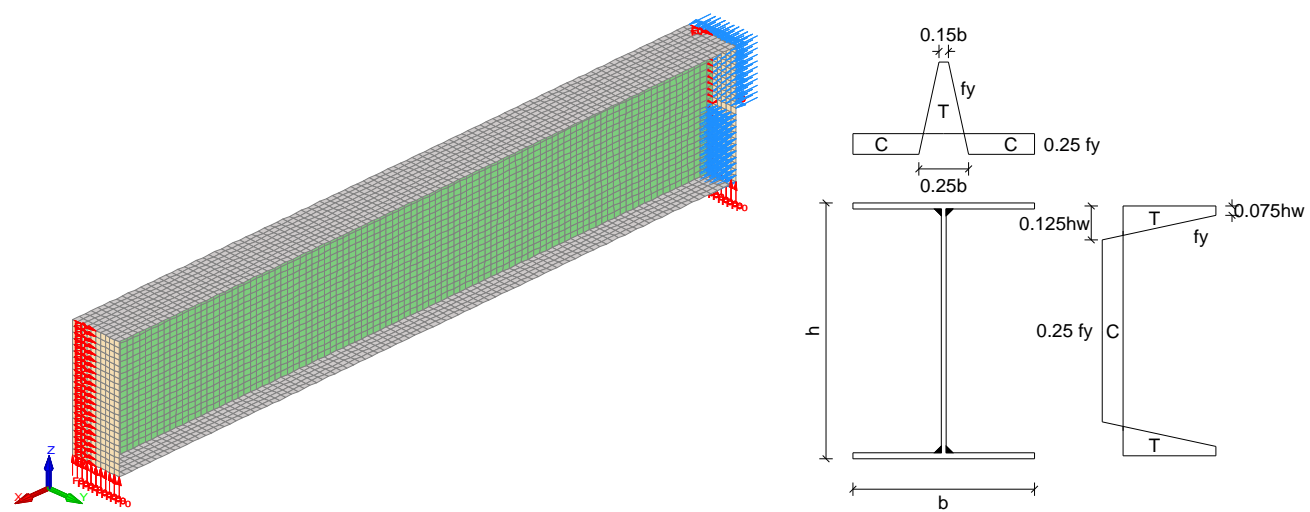

Fig. 2Shell finite element numerical model used in this study and residual stress pattern for welded profiles.

Geometric imperfections were introduced in the model affine to eigenmodesand a combination of global and local modes was done by considering the lower mode as the leading imperfection and the other one reduced to $70 \%$. The amplitude of the imperfections was considered as $80 \%$ of L/750 and the local mode has been scaled either to $80 \%$ of $b / 100$ if the maximum node displacement (in respect to the local mode) occurs in the flange and to $80 \%$ of $h_{w} / 100$ if the maximum node displacement occurs in the web. Material imperfections were accounted for in the numerical models by including the residual stresses pattern of welded profiles depicted in Fig. 2.

In this study, different temperatures have been considered $\left(350^{\circ} \mathrm{C}, 450^{\circ} \mathrm{C}, 550^{\circ} \mathrm{C}\right.$ and $\left.700^{\circ} \mathrm{C}\right)$ and assumed constant along the cross-section and the beam, to allow direct comparison with the simplified design methods.Different beam lengths were considered and a total of 687 different cases were numerically investigated. The cross-sections used are summarized in Table 2 . In this case, the effective section factor and cross-sectional resistance was calculated according to new developments on the subject presented in (Couto et al. 2015b). The proposal used in this study corresponds to the simple proposal developed in that reference which wasthe one adopted in the scope of FIDESC4.

Table 2: Summary of the cross-sections analyzed in this study (Steel grade S355)

\begin{tabular}{|c|c|c|c|}
\hline Geometry & $\begin{array}{c}\text { Dimensions (in mm) } \\
\left(\mathrm{H}_{\mathrm{w}} \times \mathrm{t}_{\mathrm{w}}+\mathrm{B} \times \mathrm{t}_{\mathrm{f}}\right)\end{array}$ & Effective section factor & New curve indication \\
\hline & $450 \times 4+150 \times 5$ & $\approx 0.57$ & L3 \\
\hline & $450 \times 4+150 \times 8$ & $\approx 0.72$ & L3 \\
\hline 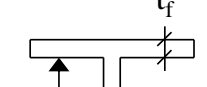 & $450 \times 4+150 \times 9$ & $\approx 0.76$ & L3 \\
\hline $\mathrm{b}$ & $450 \times 4+150 \times 10$ & $\approx 0.80$ & L2 \\
\hline $\mathrm{h}_{\mathrm{w}}$ & $450 \times 4+150 \times 12$ & $\approx 0.86$ & L2 \\
\hline \multirow{5}{*}{$\stackrel{\mathrm{b}}{\stackrel{\downarrow}{\longleftarrow}}$} & $450 \times 4+150 \times 15$ & $\approx 0.93$ & L1 \\
\hline & $450 \times 6+150 \times 8$ & $\approx 0.76$ & L3 \\
\hline & $450 \times 6+150 \times 15$ & $\approx 0.94$ & L1 \\
\hline & $450 \times 6+150 \times 16$ & $\approx 0.94$ & L1 \\
\hline & $450 \times 6+150 \times 18$ & $\approx 0.95$ & L1 \\
\hline
\end{tabular}

Note: Cross-sections calculated according to simple proposal of reference(Couto et al. 2015b). 


\section{RESULTS}

Figures 3-5, show the comparison between the numerical results and the beam design curves of Table 1. When used, the factor " $f$ " is calculated with $\chi_{L T, f i \text {, mod }}$ from Eq. (6).
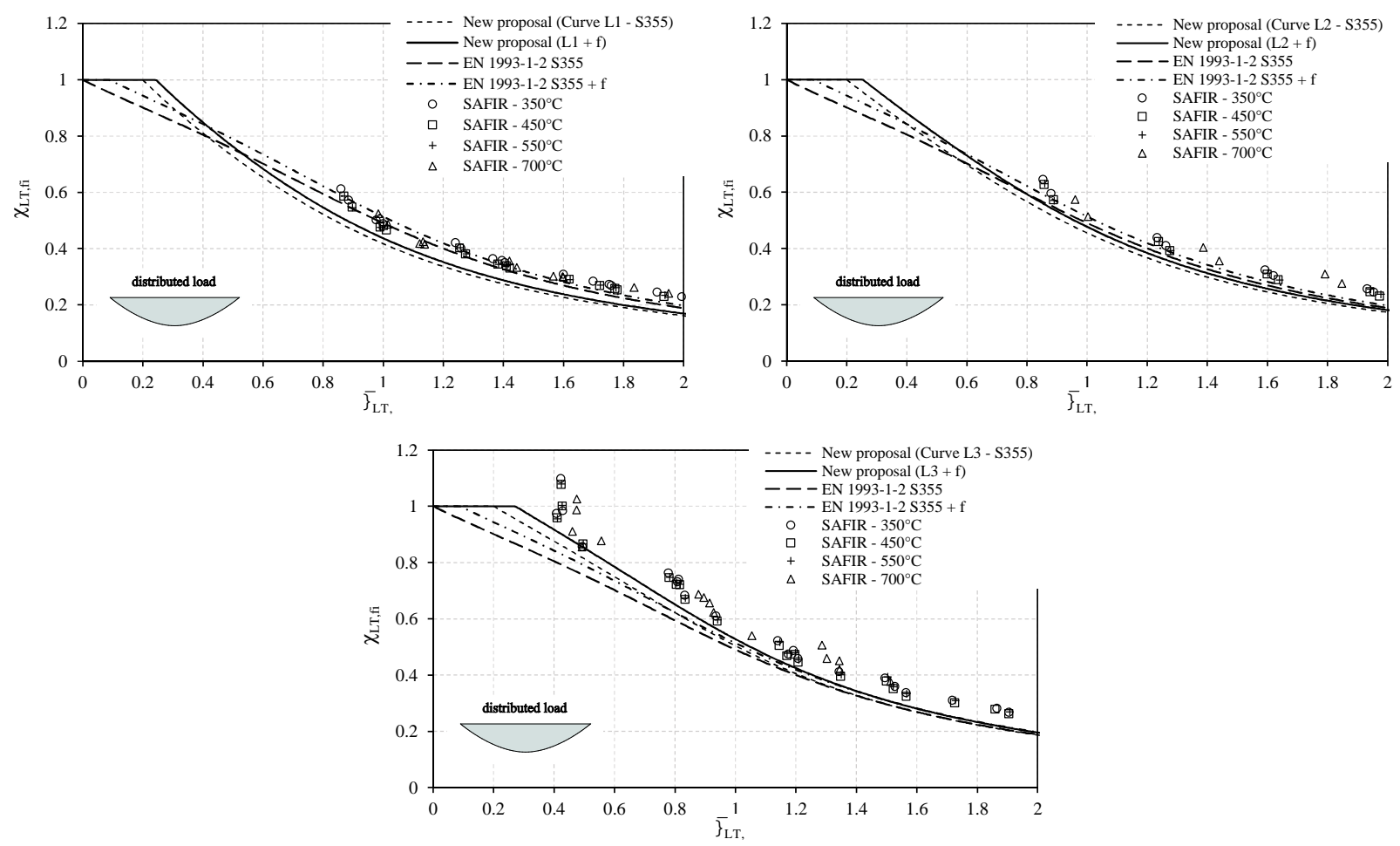

Fig. 3Comparison of the numerical results with the LTB design curves for distributed load.
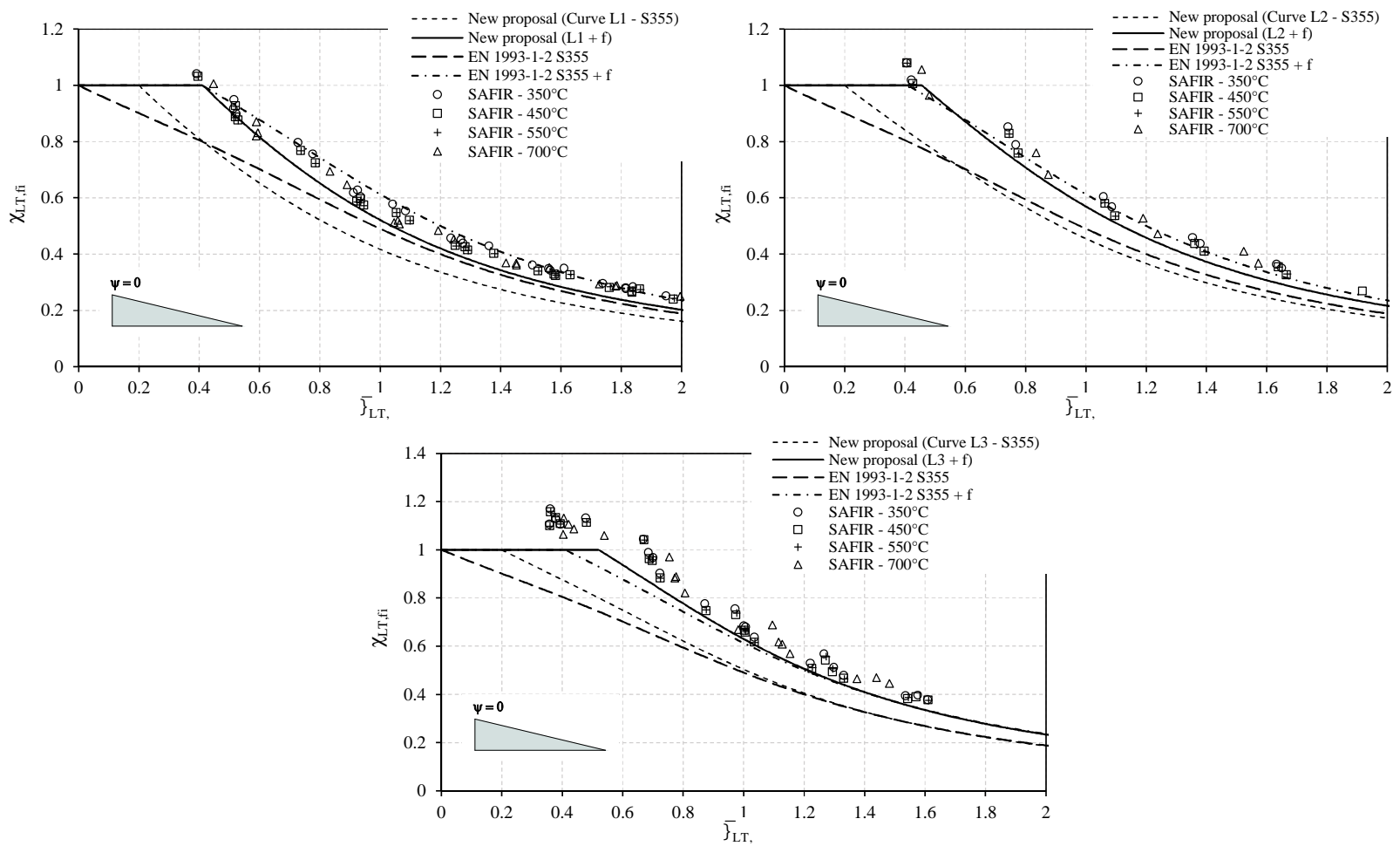

Fig. 4Comparison of the numerical results with the LTB design curves for triangular bending diagram.

For both loading cases, it is observed that the inclusion of the factor " $f$ " gives better prediction of the beam resistance when used togetherwith the proposed L1-L3 design curves. 
For the bi-triangular case (Fig.5), it is noticed that the proposed curve does not fit the numerical results when using the factor " $f$ " and several results lay on the unsafe side. In this case, it is observed that for slender cross-sections the interaction between local buckling and lateral-torsional buckling does not allow reaching the beam resistance as predicted by the factor " $f$ " that was initial developed for Class 1 and 2 cross-sections. For that reason, it is proposed to use a limitation on the factor " $f$ ' to account with this. Accordingly, this factor should be given by

$$
f=1-0.5\left(1-k_{c}\right) \text { but } f \geq 0.8
$$

As it can be seen in the Fig.5, the proposed limitation to factor " $f$ " leads to better prediction of the beam resistance and almost all numerical results are now on the safe side.In terms of the EN1993-12 beam design curve it is observed that it yields very safe results for all the loading cases but when using the factor " $f$ " inconsistent results are obtained and a considerable amount of unsafe results appear (see also Table 3).
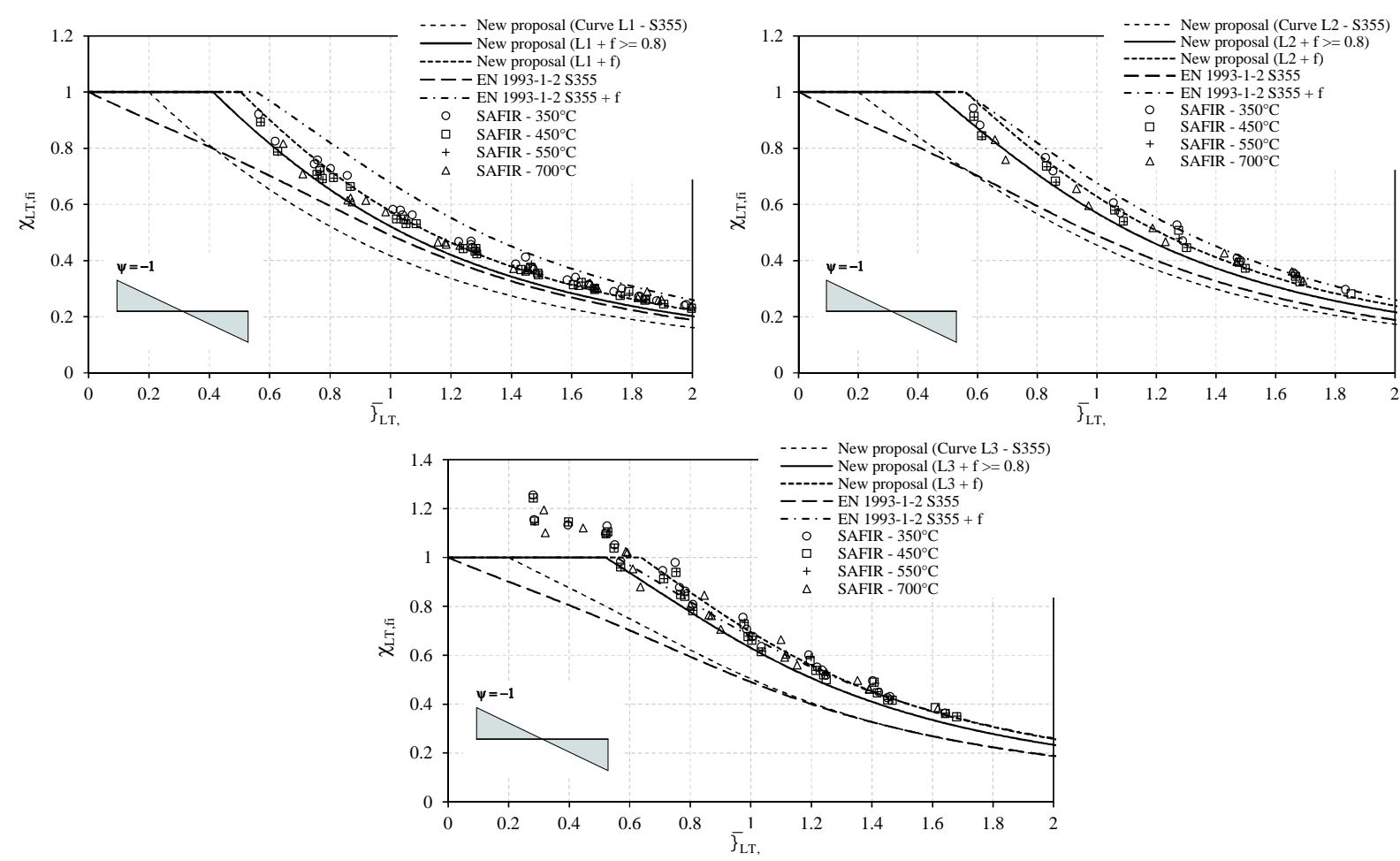

Fig. 5Comparison of the numerical results with the LTB design curves for bi-triangular bending diagram.

\section{STATISTICAL EVALUATION}

The statistical results obtained for different curves are presented in Table 2. Although not plotted in the Figs. 3-5, the LTB design curve of EN1993-1-2 and using the limitation to factor " $f$ " given byequation (7) was also considered in this table.

Table 3Statistical results of beams submitted to non-uniform bending diagrams.

\begin{tabular}{|c|c|c|c|c|c|c|}
\hline Case & LTB design curve & N Cases & Average & StdDev & Max.Unsafe & $\%$ Unsafe \\
\hline $\mathrm{i}$ & EN1993-1-2 & \multirow{6}{*}{687} & 0.80 & $7.70 \%$ & 1.04 & $1.46 \%$ \\
\hline ii & EN1993-1-2 + f (equation 6) & & 0.99 & $11.02 \%$ & 1.26 & $42.07 \%$ \\
\hline iii & EN1993-1-2 + f $\geq 0.8$ (equation 7) & & 0.95 & $8.49 \%$ & 1.15 & $30.42 \%$ \\
\hline iv & New proposal & & 0.76 & $6.28 \%$ & n.a. & $0.00 \%$ \\
\hline $\mathrm{v}$ & New proposal $+\mathrm{f}$ (equation 6 ) & & 0.93 & $8.56 \%$ & 1.18 & $19.21 \%$ \\
\hline vi & New proposal $+\mathrm{f} \geq 0.8$ (equation 7 ) & & 0.90 & $6.22 \%$ & 1.07 & $4.80 \%$ \\
\hline
\end{tabular}


It is observed thatboth theEN1993-1-2 and new proposal (casesi and iv) are too much conservative (average values of 0.80 and 0.76 ) with the new proposal being always safe sided. Considering factor " $f$ " from Eq. 6 (cases ii and v) the results now yield an average value of 0.99 for the EN19931-2 design curve and 0.93 for both cases, however a significant amount of unsafe results appear, respectively $42.07 \%$ and $19.21 \%$ for the EN1993-1-2 and new proposal, with a maximum 1.26 and 1.18. As it was mentioned in section 3, the factor " $f$ "seems not to be adequate for bi-triangular bending diagram $(\psi=-1)$. Finally, considering a limitation on the factor $f \geq 0.8$ (case iii and vi), there is some improvement on the results, but for the EN1993-1-2 still too many unsafe results exist $(30.42 \%)$. With this limitation, the new proposal yields an average value of 0.90 with just $4.80 \%$ unsafe results and a maximum of 1.07 .

\section{CONCLUSIONS}

In this work, the behaviour of beams with slender cross-sections submitted to non-uniform diagrams was numerically investigated in fire situation.

Comparison between the numerical results and the design methods of EN1993-1-2 with the respective buckling curve show that is mainly conservative for non-uniform bending diagrams but using the factor " $f$ " gives a large amount of results that lay on the unsafe side. The proposed design curves L1, L2 and L3 also demonstrated to be very conservative for non-uniform bending diagrams. In this case, the use of factor " $f$ " lead to improved results, however for the bi-triangular bending diagram it was also observed some unsafe results. Therefore it was proposed to use a limitation to this factor.

Finally, it was concluded that the proposed design curves (L1,L2 and L3) together with a factor " $f$ " limited to 0.8 could be used to design beams with slender cross-sections submitted to non-uniform bending diagram in fire situation.

\section{ACKNOWLEDGMENTS}

The work in this paper was supported by the European Commission, Research Fund for Coal and Steel in the frame of the research project "FIDESC4 - Fire Design of Steel Members with Welded or Hot-rolled Class 4 Cross-sections", Grant Agreement Number RFSR-CT-2011-00030.

\section{REFERENCES}

CEN, 2005. EN 1993-1-2, Eurocode 3: Design of steel structures - Part 1-2: General rules - Structural fire design.

Couto, C., Vila Real, P., Lopes, N., Zhao, B., 2015a. Numerical investigation of the lateral-torsional buckling of beams with slender cross sections for the case of fire. submitted to Engineering Structures.

Couto, C.,Vila Real, P., Lopes, N., Zhao, B., 2015b. Resistance of steel cross-sections with local buckling at elevated temperatures. Journal of Constructional Steel Research, 109, pp.101-114.

FIDESC4, 2014. Fire Design of Steel Members with Welded or Hot-Rolled Class 4 Cross-Section, RFCSCT-2011-00030, 2011-2014,

Franssen, J.-M., 2005. SAFIR, A Thermal/Structural Program Modelling Structures under Fire. Engineering Journal, A.I.S.C., 42(3), pp.143-158.

Lopes, N., Vila Real, P., Simões da Silva, L., Franssen, J.-M., 2010. Lateral-torsional buckling on carbon steel and stainless steel beams with lateral loads plus end moments in case of fire. In proceedings of the 6th International Conference on Structures in Fire SiF'10. East Lansing, Michigan.

Vila Real, P.M.M., Lopes, N., Simões da Silva, L., Franssen, J.-M., 2007. Parametric analysis of the lateraltorsional buckling resistance of steel beams in case of fire. Fire Safety Journal, 42(6-7), pp.416-424. 